O S M O I K OL A

\title{
Suomen kielen kehityskaudet
}

Yliopistollisessa opetustoiminnassani olen silloin tällöin tuntenut eräänlaiseksi hankaluudeksi sen, ettei suomen kielen kehityskausilla ole kyllin selviä eikä vakiintuneita aikarajoja eikä nimityksiä. Tähän vakiintumattomuuteen on varmaan tärkeimpänä syynä ollut se, että kielen kehitys on ollut yhtäjaksoista ja että sen katkominen määränimisiksi kausiksi olisi jossakin määrin mielivaltaista. Mutta vaikka kehitys onkin ollut keskeytymätöntä, ei se kuitenkaan ole ollut tasaista, tasapaksua, vaan jaksottuu selvästi erilaisiin kausiin, joista toisia luonnehtii nopea, mullistavakin muuttuminen, toisia taas hiljaisempi edistyminen. Vaikkakin eri kausien nimitykset ja aikarajat siis aina ovat osaksi ehdonvallan asioita, on periodointiin sittenkin riittävästi perusteita ja aihetta. Silksi rohkenen seuraavassa ottaa kysymyksen pohdittavaksi.

Useimpien tunnettujen sivistyskielten tutkimulksessa on vakiintunut jako kehityskausiin. Aloitan mainitsemalla esimerkkeinä muutamia tällaisia jakoja (lähteenäni vain Otavan Iso Tietosanakirja). Ruotsin kielen historia on tapana jakaa seuraaviin jaksoihin: riimuruotsi (runsvenska) 800-1225, muinaisruotsi (fornsvenska) 12251526 (jakautuu varhaisempaan eli klassiseen ja myöhempään kauteen), uusruotsi (nysvenska) 1526- (jakautuu varhaisempaan ja myöhempään uusruotsiin, rajana v. 1732). ${ }^{1}$ Saksan kielen historiassa taas mainitaan seuraavat jaksot: muinaissaksa (muinaisalasaksa ja muinaisyläsalksa 1. Althochdeutsch) 700-luvulta n. v:een 1050, keskiyläsaksa (Mittelhochdeutsch) n. 1050-n. 1500 (toisten tutkijoiden mukaan n. v:een 1350), uusyläsaksa (Neuhochdeutsch) n. 1500(toisten mukaan n. 1600-, jolloin kausi 1350-1600 erotetaan var-

1 CARL-ERIK THors, Otavan Iso Tietosanakirja 7, Keuruu 1964, palstat 741742. 
hais-uusyläsaksaksi, Frühneuhochdeutsch). ${ }^{2}$ Englannin kielen kehitys jaksotellaan seuraavasti: muinaisenglanti 1. anglosaksi (Old English, Anglo-Saxon) v:een 1100, keskienglanti (Middle English) 11001500, uusenglanti (Modern English) v:sta 1500 nykypäiviin (erikseen mainitaan vielä nykyenglanti l. Present-day English). ${ }^{3}$ Ranskan kielen historiassa erotetaan muinaisranska 800-1300-luvuilla, keskiranska (moyen français) n. v:sta 1350 (tai 1328) 1500-luvun loppuun, uus- eli nykyranska 1600-luvun alusta nykypäiviin. ${ }^{4}$

Ainoa tuntemani ehdotus suomen kielen koko historian jaksotteluksi on Heikкi OJansu un esittämä. Eräässä v. 1916 ilmestyneessä kirjassa hän julkaisi mm. esitelmänsä "Millaista suomea puhuttiin keskiaikana?", joka alkaa seuraavasti: "Jos katsomme n.s. alkusuomalaisen ajan loppuneen viimeistään $\mathrm{v}: \mathrm{n} 700$ seuduilla j.Kr.s., on meidän alettava suomen kielen erikoiskehitys tästä ajasta. Tämän 1200-vuotisen ajanjakson voimme jakaa eri aikakausiin: v a $\mathrm{rh}$ a is s u o m e e n, jonka on katsottava kestäneen v:n 1200 seuduille, k e s kiajan suomeen vv. 1200-1540, vanhaan suomeen vv. 1540 - 1800 ja ny kys u o m e en v. 1800-." ${ }_{5}$ OJansưn postuumissa kirjoituksessa "Lisiä keskiajan suomen tuntemukseen", joka sisältää "rungon keskiajan suomea käsitelleelle, Turun suomalaisessa yliopistossa 1922: n vuoden syyslukukaudella pidetylle luentosarjalle", tämä jaksottelu esiintyy hieman muuntuneena: "Suomen kielen erikoiskehitys alkaa vasta kantasuomalaisen ajan jälkeen, varhaisintaan vv. 400-500:n seuduilla j.Kr.s. Se käsittää siis noin 1400 vuoden ajan. Tämän ajan voimme jakaa kahteen yhtä pitkään jaksoon: vv. 500-1200 es ikir jallinen n.s. varhais s u o m i ja v:sta 1200 nykypäiviin asti, k i r j a 11 i n e n a i k a. Jälkimmäinen jakautuu kolmeen ajanjaksoon: vv. $1200-1540$ k eskiajan s u o m i, jolta ajanjaksolta on monta tuhatta suomenkielistä paikannimeä keskiajan latinan- ja ruotsinkielisissä asiapapereissa, u u d e n a j a $\mathrm{n}$ s u o m i vv. 1540-1800, jolta ajalta on melko runsaasti kirjallisuutta etupäässä kuitenkin vain maan läntisistä murteista sekä vuodesta

2 ERIK ERÄMetsï, OIT 7, p. 933-934.

3 Tauno Mustanoja, OIT 2, 1961, p. 930-931.

4 Tauno Nurmela, OIT 7, p. 248.

${ }^{5}$ HeIkKI OJansuU Suomen kielen tutkimuksen työmaalta I, Jyväskylä 1916, s. 24. 
1800- n y kys u o m e n aika, kirjakielen uudistumisen ja suomen kielen korkeamman sivistyksen kannattajaksi kohoamisen aika."6

Edellä mainitut vieraita kieliä koskevat jaotukset tuskin sellaisinaan soveltuvat malleiksi, sillä suomen kielen historia on siksi omalaatuinen. Myöskään OJansuun jaottelu ei ole joka suhteessa onnistunut. Seuraavassa käsittelen eri kehityskausia kronologisessa järjestyksessä.

OJANsuU jakaa jälkimmäisessä ehdotuksessaan koko kielemme historian kahteen suunnilleen yhtä pitkään jaksoon: esikirjalliseen ns. varhaissuomeen ja kirjalliseen aikaan. Rajana on vuosi 1200 . Mielestäni on vaikea antaa vuodelle 1200, summittaiselssi rajaksi käsitettynäkään, näin tärkeätä merkitystä. Tämän vuosiluvun valintahan perustuu vain siihen, että silloin alkoi vuosisata, jolta ovat peräisin suomen kielen vanhimmat kirjaanpanot. Koko 1200-luvulta ei kuitenkaan ole säilynyt muuta kuin muutama harva yksinäinen nimi vieraskielisissä asiakirjoissa. ${ }^{7}$ Siirtyminen esikirjallisesta kirjalliseen aikaan tapahtuu niin vähittäin ja sitä paitsi tietomme kaikesta Agricolaa vanhemmasta suomesta ovat niin niukat, että painettua suomenkielistä kirjallisuutta edeltävää kautta voidaan hyvin käsitellä yhtenä jaksona. Jos haluaisimme jakaa suomen kielen historian kahteen pääjaksoon, niin huomattavin taitekohta olisi pikemminkin Agricolan kirjallisen toiminnan alku. Mutta kahtiajako ei ole tarpeen. Riittää, jos sovitaan siitä, että painetun suomenkielisen kirjallisuuden alku merkitsee uuden jakson alkamista myös suomen kielen historiassa. Koska ensimmäisen suomenkielisen painotuotteen ilmestymisvuotta ei aivan varmasti tiedetä ${ }^{8}$, voimme tyytyä sanomaan, että rajana on n. v. 1540.

Mikä nimitys parhaiten luonnehtisi tätä suomen kielen vanhinta kehityskautta? Muiden kielten tutkimuksen antamaa mallia noudattaen voisi ajatella nimitystä "muinaissuomi". Tällä sinänsä hyvällä ja luontevalla nimityksellä on kuitenkin eräs varjopuoli. Jos seuraavan kauden nimityksenä säilytetään jo vakiintunut "vanha (kirja-) suomi", olisi vieraille kielille käännettäessä vaikea pitää näitä kahta

${ }^{6}$ Satakunta VI, Porvoo 1926, s. 37-38.

7 Ks. OJansuu Suomen kieleu tutkimuksen työmaalta I s. 24.

\& Tästä kysymyksestä ks. NıILo IKola Agricolan ensimmäisen kirjan ilmestymisaika, Vir. 1950 s. 4 -. 
nimitystä erillään. Voitaisiin ehkä kylläkin ajatella, että "muinaissuomi" olisi englanniksi "Ancient Finnish", "vanha (kirja)suomi" taas "Old (Literary) Finnish". Mutta tämän kanssa ristiriidassa on se, että "Old English" vakiintuneen käytännön mukaisesti suomennetaan sanalla "muinaisenglanti". Myös saksan "Althochdeutsch" käännetään sanalla "muinaisyläsaksa", vaikka "alt"-sanan yleisin vastine on "vanha". Suomen kielenkin tutkimus on nykyään sen verran kansainvälistä, ettei tätä hankaluutta voi merkityksettömänä sivuuttaa. Siksi ehdottaisin, että OJANsưn hieman toisessa merkityksessä käyttämä varhaissuomi (englanniksi se voisi olla Early Finnish, saksaksi Frühfinnisch) omaksuttaisiin suomen kielen erikoiskehityksen alusta. n. v:een 1540 ulottuvan kehityskauden nimitykseksi. ${ }^{9}$

Seuraavan kauden kieltä OJANsuU sanoo uudemmassa ehdotuksessaan "uuden ajan suomeksi". Tämä nimitys edellyttäisi, että nykysuomikin kuuluisi tähän kielen kehityskauteen. Näin ollen tämä ei ole adekvaatti nimitys kehityskaudelle, joka päättyi 1800-luvun alussa tai alkupuolella. Vieraiden kielten tutkimusta esikuvana pitäen voitaisiin valita jokin "keskisuomi" tai "varhaisempi uussuomi", mutta nämä olisivat oudon kaikuisia ja vaatisivat antamaan seuraaville kausille nimitykset, jotka olisivat vähemmän tarkoituksenmukaiset kuin ne, joita edempänä ehdotan. Näin ollen voidaan Agricolasta alkavan kauden nimityksenä hyvin säilyttää jo vakiintunut vanha kirjasuomi tai OJANsuUnkin ensin ehdottama vanha suomi (engl. old [Literary] Finnish, saks. altes Schriftinnisch, Altfinnisch). ${ }^{10}$

3 LAURI HAKULINEN on käyttänyt sanaa "esisuomalainen" kantasuomea lähinnä seuraavaan aikaan viittaavana: "_ _ yhä vallitsevana pidettävän käsityksen mukaan varsinaissuomalaisten ja lämäläisten rinnalla olivat kolmantena 'esisuomalaisena' heimoaineksena heidën itäpuolellaan asuneet karjalaiset." $\left(\mathrm{SKRK}^{2}\right.$ s. 11). Sekaannusten välttämiseksi olisi tämä sana mielestäni kuitenkin varattava siihen merkitykseen, johon se jo on vakiintunut ja joka ilmenee esim. Nykysuomen sanakirjan sana-artikkelista esisuomi: "esi-isiemme käyttämä, kantasuomea (lähinnä) edeltänyt kielimuoto." Vrt. myös esim. PaAvo RaviLA, FUF 27 s. 73 ; LaURI Posti, FUF 31 s. 1-; MatTi KuUsi, Suomen kirjallisuus I, Keuruu 1963, s. 31. - Vaikkakin siirtyminen kantasuomesta suomen kieleen on tapahtunut hyvin vähittäin, ei mielestäni ole aihetta sijoittaa kantasuomen ja varhaissuomen väliin erikseen nimettävää kielen kehityskautta. Tämä olisi tarkoituksetonta jo siitä syystä, että tietomme noista vaiheista ovat perin epämääräiset.

${ }^{10}$ Ks. esim. Rapola, Suomen kirjakielen historia I, Helsinki 1933, s. 16. 
Kielen kehityksen jaksottelun pohjaksi on - esikirjallista aikaa lukuunottamatta - tietenkin otettava historia; kirjakielihän on ainoa kielimuoto, jonka kehitystä voimme välittömästi seurata. Näin on laita muidenkin kielten tutkimuksessa.

Milloin sitten vanha suomi muuttui seuraavan kauden kieleksi? OJANSUU asetti rajaksi vuoden 1800, josta hän katsoi nykysuomen ajan alkavan. Koko viime vuosisadan liittäminen nykysuomen kauteen lienee ollut vielä OJANsuUn aikana paremmin perusteltavissa kuin nykyään. Kirjakielessämme tapahtui viime vuosisadalla muutamien vuosikymmenien aikana siksi mullistava kehitys, ettemme mielestäni voi katsoa nykysuomen alkaneen ennen kuin tuon murroskauden jälkeen. Toisaalta murroskauden kieli eroaa myös vanhasta kirjasuomesta siksi jyrkästi, että on tuskin mahdollista ulottaa vanhan suomen aikaa siihen saakka, mistä lasketaan nykysuomi alkavaksi. Tarkoituksenmukaisimmalta tuntuu, että vanhan suomen ja nykysuomen väliin sijoitetaan erityinen kehityskausi. Se jää tosin muihin verrattuna lyhyeksi, mikä ei kuitenkaan tunnu luonnottomalta, kun kysymys on näin tuoreesta historiasta.

OJANsuU siis katsoi edellisen kehityskauden päättyneen v. 1800, mutta juuri vuosisadanvaihteen asettamiseen rajaksi on tuskin riittäviä perusteita. Ns. murteiden taistelu on epäilemättä tärkeimpiä seuraavaa kehityskautta luonnehtivista ilmiöistä, mutta senkin alkamisajasta on esitetty erilaisia käsityksiä. JuLIUs KRoHNin "Suomalaisen kirjallisuuden vaiheissa" katsotaan "murteitten taistelun ajan" alkaneen v. 1809, Haminan rauhan vuonna. ${ }^{11}$ Saman vuoden merkitsee OJANsuUkin Tietosanakirjaan kirjoittamassaan artikkelissa murteiden taistelun alkukohdaksi. ${ }^{12}$ Kummassakin tapauksessa on kysymys kirjallisuuden eikä kielen historiasta. Tietenkin Suomen valtiollisen aseman muuttuminen oli tärkeä syy siihen, että kirjakielenkin kehitys suuntautui uusille urille, mutta kuitenkaan ei v. 1809 eikä vielä lähimpinä seuraavinakaan vuosina tapahtunut kielen kehityksessä mitään erikoista. On epäilemättä tarkoituksenmukaisempaa, jos kielen kehityskausien rajat perustuvat todella kielen elämän ilmiöihin eivätkä valtiollisen historian tapahtumiin.

MARTTi RAPOLA on entistä täsmällisemmin määritellyt murteiden

11 J ULIUS Kroнn Suomalaisen kirjallisuuden vaiheet, Helsinki 1897, s. 177.

12 Tietosanakirja 6, Helsinki 1914, p. 828. 
taistelun ajalliset rajapyykit. Hän tulee siihen tulokseen, että jos "taistelua" on pidettävä "niin luonteenomaisena, että sen mukaan koko vaihetta on nimitettävä, pantakoon alkuvuodeksi vaikkapa 1817, jolloin K. A. Gottlund 'Svenska Literatur-Tidningissä' sinkosi esiin eräitä provosoivia väitteitä".13 Kun kuitenkin on vaikea määritellä kielen historian kehityskausia yhden vuoden tarkkuudella ja kun "murteiden taistelu" ei ole ainoa tälle kehityskaudelle luonteenomainen ilmiö, voitaisiin mielestäni sopia siitä, että uusi kausi alkoi n. v. 1820. Varsinaiseen vauhtiin itse "murteiden taistelukin" pääsi juuri v. 1820, jolloin ReinHold von BEckeR esitti Turun Viikkosanomissa uudistusohjelmansa. ${ }^{14}$ Vasta 1820 -luvulla näyttää varsinaisesti päässeen käyntiin myös se määrätietoinen kielemme sanaston kartuttaminen, joka "murteiden taistelun" ohella on leimaa-antava tälle kaudelle. Tällä vuosikymmenellä voN BEcKER sepitti huomattavan joukon uudissanoja, ja juuri v. 1820 alkoi "Turun Viikko-Sanomat" ilmestymisensä hänen toimittamanaan. Vuosisadan kahta ensimmäistä vuosikymmentä voitaneen luonnehtia kielen historiassa hiljaiselon ajaksi, edellisen vuosisadan kehityksen jatkoksi.

Kysymyksen tämän n. v. 1820 alkaneen kehityskauden nimityksestä jätän toistaiseksi avoimeksi ja koetan ensin ratkaista, mihin sijoitetaan kauden loppuraja. KRoHN katsoo kirjallisuudenhistoriassaan "murteitten taistelun ajan" päättyneen v. 1844, jolloin "Saima" alkoi ilmestyä ja Snellmanin kansallinen herätystyö alkoi. ${ }^{15}$ Kielen historian kannalta tämä ei kuitenkaan ole mikään rajavuosi. OJANsUU taas katsoo mainitussa Tietosanakirjan artikkelissaan "murteiden taistelun ajan" päättyneen jo v. 1835 eli Kalevalan ilmestymisvuotena. ${ }^{16}$ Kuten RAPoLA huomauttaa, niin Kalevalan ilmestyminen kyllä sopii merkkivuodeksi kirjallisuushistorialliselta, mutta ei kielen kehityksen kannalta. ${ }^{17}$ RAPoLA puolestaan sanoo, että on makuasia, milloin "murteiden taistelun" katsotaan kokonaan siirtyneen historiaan, ja että joku ehkä väittäisi sen vaikuttavan kirjasuomen pohjavesissä

13 MartTr Rapola Murteiden taistelu -- mitä se oli ja mitä se ei ollut, Kalevalaseuran vuosikirja 36, Helsinki 1956, s. 15-.

${ }_{14} \mathrm{Ks}$. KROHN Suomalaisen kirjallisuuden vaiheet s. 194; RAPOLA, Kalevalaseuran vuosikirja 36 s. 20 ; Suomen kirjallisuus III, Keuruu 1964, s. 41.

1s KroHN mts. 177, 331, 336 ym.

${ }_{10}$ Tietosanakirja 6 p. 828.

17 Kalevalaseuran vk. 36 s. 20. 
tänä päivänä. "Joka tapauksessa", hän jatkaa, "on helppo todeta julkisten oikeakielisyyskiistojen olleen 1850:n aikoihin aiheiltaan suureksi osaksi toisia ja toisenlaisia kuin paria kolmea vuosikymmentä aikaisemmin."18 Tämän mukaan voitaisiin katsoa "murteiden taistelun" päättyneen n. v. 1850.

Ei kuitenkaan olisi tarkoituksenmukaista asettaa puheena olevan k i e l e n kehityskauden loppurajaa vuosisadan puoliväliin. Se olisi liian varhainen nykysuomen kauden alkurajaksi, ja sitä paitsi kirjasuomen nopea kehitys jatkui toisella lohkolla "murteiden taistelun" päätyttyäkin. Jo "murteiden taistelun aika" oli samalla kirjakielen sanaston nopean kartuttamisen aikaa, mutta tämä työ oli vielä olennaisesti kesken silloin, kun murteiden välinen tasapaino jo oli saavutettu. Vetoan jälleen RApoLAan, jolle kuuluu pääansio tämänkin vaiheen selvittelyssä. Hän lausuu: "Pääasiallisesti viime vuosisadan kahden ensimmäisen kolmanneksen kuluessa kirjasuomen sanavarat saivat sen täydennyksen, joka teki vanhasta uuden." ${ }^{19}$ Edelleen: "Uusia sanoja on omaksuttu käytäntöön myöhemminkin, enemmänkin kuin puheenaolevana aikana, mutta tyypilliseksi siirtymäkaudeksi, uuden aikakauden alkuvaiheeksi murteiden taistelukauden ja sitä lähinnä seuraavan aja leimaa silloisen sanasadon perustava, yleissivistyksellinen luonne. Osittain tämän luonteen säilytti vielä 1800-luvun loppupuolen ja seuraavan sataluvun alkupuolenkin sanaston kasvu, mutta painopiste alkoi silloin jo olla toisaalla. Voidaan väittää, että kirjasuomi 1870: een mennessä oli saanut hallintaansa melkoiset sivistyskielen mahdollisuudet, sen välttämättömimmät välineet. Se kykeni palvelemaan sivistyselämää kaikilla keskeisillä aloilla. Suomenkielinen oppikoulu oli olemassa, suomea puhuttiin eräissä johtavissa sivistyskodeissa, suomenkielinen sanomalehdistö oli kehittynyt ruotsinkielisen verroille, edustuskelpoinen yhteiskunnallis-sivistyksellinen aikakauslehti Kirjallinen Kuukauslehti seurasi valppaasti 'suuren maailman' asioita, Aleksis Kivi oli kirjoittanut monumentaaliset tuotteensa, suomalainen kansallisteatteri oli perusteilla jne." Tämän jälkeen oli pääpaino erikoisalojen sanaston kehittelyssä. ${ }^{20}$ Olen lainannut RAPoLAa näin pitkälti siksi, että sitaatti

\footnotetext{
${ }^{18}$ Kalevalaseuran vk. 36 s. 23 ; vrt. O. IkoLA Ural-altaische Jahrbücher XXXIV, 1962, s. 12.

19 RAPOLA Vanha kirjasuomi ${ }^{2}$, Forssa 1962, s. 112.

${ }^{20}$ R.APOLA Vanha kirjasuomi ${ }^{2}$ s. 115-116; ks. myös O. IroLA UAJb XXXIV s. 17 ,
} 
samalla valaisee niitä seikkoja, joiden takia tämän kielen kehityskauden jälkimmäinen rajapyykki on syytä asettaa "murteiden taistelun” päättymistä myöhempään ajankohtaan.

Edellä olevassa RAPoLAn sitaatissa on mainittu seikkoja, joiden nojalla rajan asettaminen $n$. vuoteen 1870 näyttää olevan vankasti perusteltua. Toisena mahdollisuutena voisi olla v. 1880, joka asetettiin rajakohdaksi Nykysuomen sanakirjan toimitustyössä ja joka siis tässä yhteydessä on katsottu tavallaan "nykysuomen" alkurajaksi. ${ }^{21 .}$ Toistaiseksi näyttää kuitenkin siltä, että taitekohdaksi paremmin sopii v. 1870 .

Kun katsomme tämän kehityskauden kestäneen n. 1820-n. 1870, ei "murteiden taistelu" enää riitä yksinään sitä luonnehtimaan. Muutenkin jokin "murteiden taistelun ajan suomi" olisi kovin hankala ja erikoislaatuinen kielen kehityskauden nimi. Kun kyseessä on lyhyt, nykysuomea edeltävä siirtymäkausi, voitaisiin tunnettujen esikuvien mukaan (esim. saksa Frühneuhochdeutsch, engl. Early Modern English) valita nimitys varhaisnykysuomi (englanniksi Early Modern Finnish, saksaksi Frühneufinnisch). ${ }^{22}$ Vaikkakin nimitys on suomen kielen tutkimuksessa aivan uusi ja siksi voi aluksi tuntua oudolta, niin sillä olisi puolellaan merkittäviä etuja, ennen kaikkea käytännöllisyys.

Tämän kehityskauden päättymisestä nykypäiviin ulottuisi sitten nykysuomen aika (engl. Modern Finnish, saks. Neufinnisch).

Ehdotukseni suomen kielen historian jaksotteluksi olisi siis seuraava:

Varhaissuomi n. vuoteen 1540.

Vanha (kirja) suomi n. 1540-n. 1820.

Varhaisnykysuomi n. 1820-n. 1870.

Nykysuomi n. 1870-.

${ }^{21}$ Ks. Vir. 1928 s. 355.

22 Nimitystä on minulle ehdottanut prof. Hans Fromm (München). 


\section{Osmo Ikola: Periods of development in the Finnish language}

There is no accepted manner of dividing the history of the Finnish language into periods of development. The present writer has studied the question from different points of view and proposes the following as a result:

1. Early Finnish (Finnish varhaissuomi, German Frïhfinnisch) from the beginning of the independent development of Finnish during the first thousand years A.D. until c. 1540. Finnish literary remains date from the 13th century from which time certain Finnish proper names have survived in foreign texts. As many as several thousand such names have survived from the 14th and 15th centuries, but the oldest coherent Finnish texts are manuscripts dating from as late as the 16th century.

2. Old (literary) Finnish (F. vanha (kirja) suomi, G. Altfinnisch or altes Sehriftfinnish) e. 1540 -c. 1820 . This period is reckoned to start with the appearance of the first printed books in Finnish, written by Michael Agricola.

3. Early Modern Finnish (F. varhaisnykysuomi, G. Frïhneufinnisch) c. 1820c. 1870. This period was one of rapid development for literary Finnish, the vocabulary of which grew considerably. It was also the period of a dispute as to whether literary Finnish should follow the eastern or western dialect. With the close of this period the Finnish language was sufficiently developed for use in all the more important fields of cultural life.

4. Modern Finnish (F. nykysuomi, G. Neufinnisch) c. 1870 onwards. There has been remarkable development in this period too, but it has not been so rapid nor so radical as in previous periods. 